\title{
Accelerating and Mitigating Postharvest Losses in Nigeria Through an Automated Hydrid Dryer
}

\author{
Suleiman Abubakar Ibrahim, Atanda Emmanuel Olugbenga, Eriakha Ehis Collins \\ Department of Agricultural \& Bioenvironmental Engineering, Auchi Polytechnic, Auchi, Edo State, Nigeria
}

\begin{abstract}
Africa has the world's biggest population of people without access to electricity, with an estimated 600 million people without access today and 700 million by 2030. Currently, almost two-thirds of Nigeria's population lacks access to reliable energy, and the majority of rural regions are not connected to the national grid. Given these staggering statistics, farmers in Nigeria, especially those in the production section are exposed to postharvest losses annually. Every year, Nigeria loses N3. 5 trillion in post-harvest losses due to a lack of suitable storage facilities and bad road conditions across the country. To mitigate this trend and help accelerate the adoption and acceptability of technology that will solve these postharvest problems, a hybrid dryer is developed. This research involved the development of an automated passive, hybrid dryer developed in the Federal Polytechnic Auchi, Edo State Nigeria with a research grant from TETFUND. A detailed AUTOCAD model for the dryer is developed and validated through experimentation. Energy and environmental analysis of the proposed dryer system were equally evaluated. Two crop produce, yam and tomatoes were used in evaluating the machine. One of the major highlights of the machine is that it is an automated dryer with power sources from both solar and mains supply. The drying process was conducted during the day, and it was compared with open sun drying and oven drying. The highest solar drying temperature obtained under the same condition for both yam and tomatoes were $38{ }^{\circ} \mathrm{C}$. At the average solar radiation of $2462 \mathrm{~W} / \mathrm{m}^{2}$ and air flow rate of $19.74 \mathrm{~kg} / \mathrm{s}$, the thermal efficiency of the hybrid dryer was obtained at $23.74 \%$. It was observed that the thermal efficiency of the collector was high when compared to similar dryers from literatures. Further analysis to established the commercial scalability of the system is however, recommend.
\end{abstract}

Keywords: Postharvest losses, Hydrid, Automated, Accelerate, Mitigate

DOI: $10.7176 /$ ISDE/12-4-02

Publication date:October $31^{\text {st }} 2021$

\subsection{Introduction}

The Nigerian electrical supply system's epileptic state is a major source of post-harvest losses, which is extremely dangerous and has a direct socio-economic impact on the entire population and the country's GDP. The Table 1 below, shows the typical electricity access in Nigeria, especially its rural areas. Given the nature of agricultural produce, especially fruits and vegetables, hey are prone to damage and losses with such electricity supply. Due to the biochemical processes, many agricultural goods have significant moisture content at harvest, making them sensitive to microbial and other deterioration. As a result, drying or dehydration activities must be carried out as preventative steps to reduce the product's moisture content and assure food safety (Fodor, 2006). Drying is the removal of water from food in order to prevent metabolic reactions and microbiological growth. Drying extends the product's shelf life, allowing it to be sold during off-seasons. Sun drying in the open air is one of the oldest and most well-known methods for preserving agricultural products for lengthy periods of time (Ekechukwu and Norton, 1997). Certain innovative approaches, such as hot air drying or dielectric heating, have been introduced to improve the efficiency of the drying process. However, these processes necessitate a large amount of energy, which is often derived from traditional energy sources such as fossil fuels. With the depletion of fossil fuels and the rise in energy prices, renewable energy sources for drying are becoming increasingly important (Fodor, 2006).

Table 1: Electrification rates in Nigeria and Sub-Saharan Africa(Blimpo \& Cosgrove-Davies, 2019)

\begin{tabular}{|l|l|l|}
\hline \multicolumn{1}{|c|}{ Region } & Sub-Saharan Africa & \multicolumn{1}{c|}{ Nigeria } \\
\hline Population without electricity & 621 million & 93 million \\
\hline Overall electrification rate (\%) & 32 & 45 \\
\hline Urban electrification rate (\%) & 59 & 55 \\
\hline Rural electrification rate (\%) & 16 & 35 \\
\hline
\end{tabular}

Over half of fresh fruits and vegetables produced in Sub-Saharan Africa and Southeast Asia are lost or discarded, according to the UN Food and Agriculture Organization, with nearly half of these losses occurring during postharvest operations(Teale, 2021). Without the knowledge and appropriate technologies to properly store, transport, conserve, and process fresh fruits and vegetables, the cost of fresh fruits and vegetables rises dramatically, forcing low-income households, who spend more than half of their income on food, to prioritize less nutritious staple crops for food security. According to research by the International Food Policy Research 
Institute (IFPRI), lowering loss/waste by $10 \%$ in developing countries could reduce fruit and vegetable prices by $14 \%$, the number of people at risk of hunger by $11 \%$, and child undernutrition by $4 \%$ by 2050 (Teale, 2021). GAIN and its partners founded the Postharvest Loss Alliance for Nutrition (PLAN) in 2015 to bring together a diverse group of public and commercial sector players working to eliminate nutritional food loss across the supply chain(Teale, 2021). PLAN's objective is to organize quantifiable initiatives to alleviate perishable and nutritious food supply chain losses and promote access to these items for communities, especially low-income households(Teale, 2021). This automated hybrid dryer will no doubt provide hat much needed technology to mitigate postharvest losses. A novel hybrid solar-electrical dryer of wood with heat recovery system is proposed. A detailed AUTOCAD model for the dryer is developed and validated through experimentation. Energy and environmental analysis of the proposed dryer system were equally evaluated. The PVT air collector for electrical/thermal energy production is suitable for food dryers. This technology further elucidates the gains of adopting renewable energy technologies across sectors. Africa is embracing this technology use in an accelerated manner. As elucidated in the Figure 1 below, the solar radiation level (GHI) in Nigeria creates the enormous potential for the massive adoption of solar technology as a renewable enrgy source.

Renewable Energy sources like small-scale stand-alone Solar PV systems and solar thermal energy sources are being used in countries like South Africa, Kenya, Egypt, Morocco, Algeria, etc, for food preservation in rural communities(Lamrani et al., 2021). The electricity from solar energy technologies could come from the thermal system (Concentrated Solar Power) or Photovoltaic (PV). The solar thermal technologies could be applied in heating of houses, drying of crops while photovoltaic are useful in remote areas to drive rural television, streetlight, radio, refrigerator, pumping of water, powering cameras for security etc. It could also assist in supplying water to remote areas for agricultural purposes. The total solar radiation incident on the Nigeria surface is stated to be around $12.6 \mathrm{MJ} / \mathrm{m}$ days in coastal zones but it is affected by the change in climate(Ahmadi et al., 2021; Blimpo \& Cosgrove-Davies, 2019).

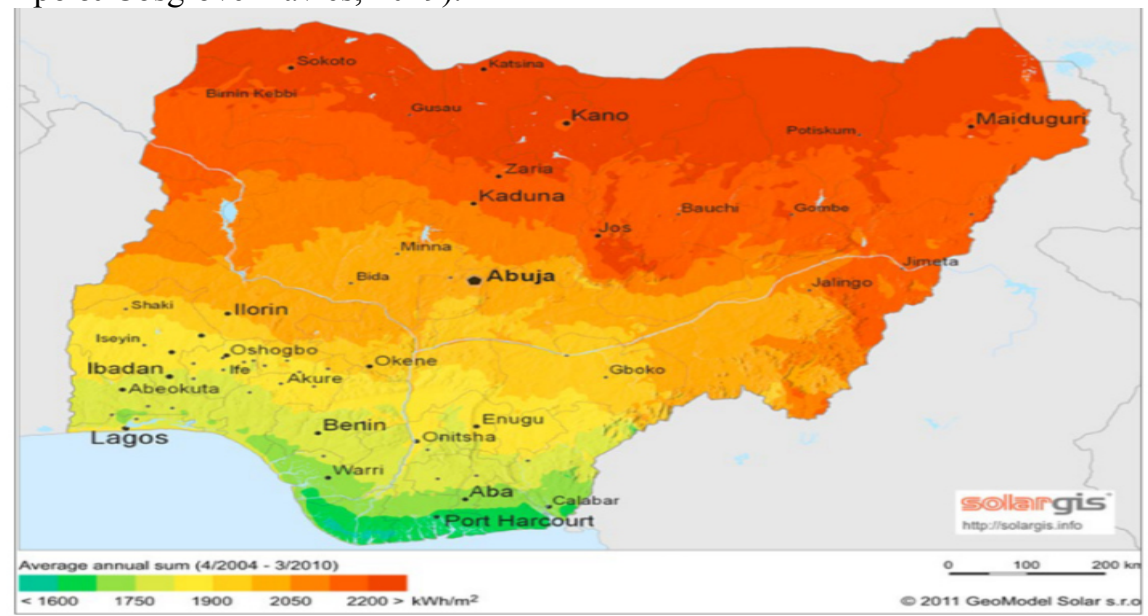

Figure 1: Solar radiation level (GHI)(Blimpo \& Cosgrove-Davies, 2019)

Food preservation has recently attracted global interest as it helps in bridging the gap of shortage during scarcity of food materials, such as tomatoes, in the quest to meet the sustainable development goals (SDGs 2030), especially SDG No. 2, which is concerned with hunger alleviation, achieving food security, improving nutrition, and promoting sustainable agriculture before the year 2030(Ahmadi et al., 2021; Lamrani et al., 2021; Teale, 2021). Tomatoes and other perishables are crucial for human health and nutrition because they include key nutrients like as vitamin $\mathrm{C}$, potassium, vitamin $\mathrm{K}$, fiber, carbohydrate, and antioxidants, all of which help to reduce the risk of cancer and heart disease. Tomatoes, unfortunately, are not only seasonal but also highly perishable. As a result, there is always an unacceptable gap between harvest and off-season times because they are frequently consumed quickly during harvest due to a lack of storage facilities, particularly in rural communities of developing nations such as Nigeria where electricity is scarce. As a result, it is critical to seek out alternative methods of preserving this food material in order to create a larger market for tomatoes, allowing consumers and traders to purchase them all year long while also providing a higher profit margin for rural and sub-urban farmers in developing countries(Blimpo \& Cosgrove-Davies, 2019).

In Nigeria, the technology of solar thermal drying is not new. The traditional means of drying in open sun is not new to many homes in the rural settings in the country. Sun drying is one of the most widespread and cheap methods practiced by most developing and underdeveloped countries, especially in tropics, where good sunshine hours available throughout the year(Ahmadi et al., 2021; Blimpo \& Cosgrove-Davies, 2019). In this process food commodities are laid on a platform in a thin layer for uniform drying. The sun's heat not only reduces the moisture level as desired, but also kills insects present in the food product. Sun drying has certain limitations as it is dependent on the weather and sunshine hours. During uncertain rain and precipitation, the materials are not 
dried properly, which causes microbial growth and other qualitative deteriorations(Mohammed et al., 2020). The open air drying or sun drying has many limitations and due to the rise of fuel prices, depletion of fossil fuels, the use of modern drying technologies are not economical for drying agricultural product. Hence solar drying systems have been developed as a successful and economical tool for drying agricultural product. Solar drying is achieved by direct sun radiation and greenhouse effect. The solar energy received by the drying chamber is dependent on the sunshine hours, climate, weather, atmospheric clearness, and location.

Tiwari and Rajeev (2011(Tiwari, 2011)), these solar driers may be again sub-grouped under three categories: (i) Integral type (direct mode), (ii) distributed type (indirect type), and (iii) mixed mode. In a direct type, solar drying material is placed in a drying chamber having a transparent cover through which solar radiation enters and heats the food materials to be dried. In an indirect mode, solar energy is captured by a solar collector, which in turn heats the air(Mohammed et al., 2020; Tiwari, 2011). This heated air is then passed to the drying cabinet/chamber. In mixed mode, solar energy is collected in separate solar collector and heated air is then passed over the drying material. The drying materials absorb the solar energy directly through the transparent cover and walls(Tiwari, 2011).

The drying process usually takes a long time, thus causing infestation from insects, birds, and animals. Also, this method of drying requires a large area. The largest dryers are typically utilized "off-farm," in elevators, and are continuous in nature: In Europe, mixed-flow dryers are favoured, but in some countries like the United States, cross-flow dryers are preferred. Continuous flow dryers have the capacity to dry up to 100 metric tons of grain per hour(Mohammed et al., 2020; Udomkun et al., 2020). In continuous dryers, the air must penetrate a depth of grain ranging from $0.15 \mathrm{~m}$ in mixed flow dryers to $0.30 \mathrm{~m}$ in cross-flow dryers. Batch dryers are primarily utilized "On-Farm," especially in the US and Europe(Udomkun et al., 2020). They usually consist of a bin with heated air flowing horizontally from an internal cylinder through an inner perforated metal sheet, then through a $0.50 \mathrm{~m}$ thick annular grain bed in radial direction (coaxial with the internal cylinder), and finally across the outer perforated metal sheet before being discharged to the atmosphere. Depending on how much water needs to be removed, the type of grain, air temperature, and grain depth, drying timeframes can range from 1 to 4 hours(Udomkun et al., 2020).

Among the processes applied for fruit and vegetable preservation, drying has received special attention as this method is currently regarded as the most common way for obtaining food and pharmaceutical products(Mohammed et al., 2020). It mainly aims at extending the product and/or its constituent's shelf life by preventing the growth of microorganisms (Mohammed et al., 2020). There are numerous drying techniques offered to dehydrate different kinds of raw materials in order to obtain products of a high-quality dependent on processing parameters, this project considers hybrid dryers which combines two or more drying processing for composite result.

Drying of products can thus be obtained by circulating air at varying degrees of heat through a mass of gram. As it moves, the air imparts heat to the grain, while absorbing the humidity of the outermost layers. In terms of physics, the exchange of heat and humidity between the air and the product to be dried is seen in the following phenomena:

- $\quad$ heating of the grain, accompanied by a cooling of the drying air;

- $\quad$ reduction in the moisture content of the grain, accompanied by an increase in the relative humidity of the drying air. But this process does not take place uniformly.(Mohammed et al., 2020)

Indeed, the water present in the outer layers of grain evaporates much faster and more easily than that of the internal layers. Thus, it is much harder to lower the moisture content of a product from 25 to 15 percent from 35 to 25 percent(Mohammed et al., 2020). It would be a mistake to think that this difficulty be overcome by rapid drying at high temperature. In fact, such drying conditions create internal tensions, producing tiny cracks that can lead to rupture of the grains during subsequent treatments. According to Mohammed et al., (2020), for drying grain, essentially two methods are used:

- natural drying,

- artificial drying.

Both of them have advantages and disadvantages, and no ideal method exists that permits all needs to be met.

\section{Material and Methods}

\subsection{Design Concept of the Hybrid Dryer}

Solar dryers are available in various ranges of size and design and are used for drying of various agricultural products. Various types of Dryers are available as per requirement of farmers. Primarily all the drying systems are classified on the basis of their operating temperature ranges that is High Temperature solar dryer and Low Temperature Solar dryer. The following criteria as elucidated by Mohammed et al., (2020) are required for the classification of solar dryer: -

- Air movement mode 
- Insulation exposure

- Air flow direction

- Dryer arrangement

- Solar contribution

- Type of fruit to be dried

In this work, a novel indirect solar-electrical dryer for crops integrated with hybrid PVT solar air collector and heat recovery system is presented and investigated. The design of the proposed dryer system is given in Fig.2. This system is composed mainly of a well-insulated drying chamber, a hybrid PVT solar air collector, an air-to-air HRS, an auxiliary heater and fans. The studied dryer works as in agricultural industry in forced convection and according to the developed operating process presented below:

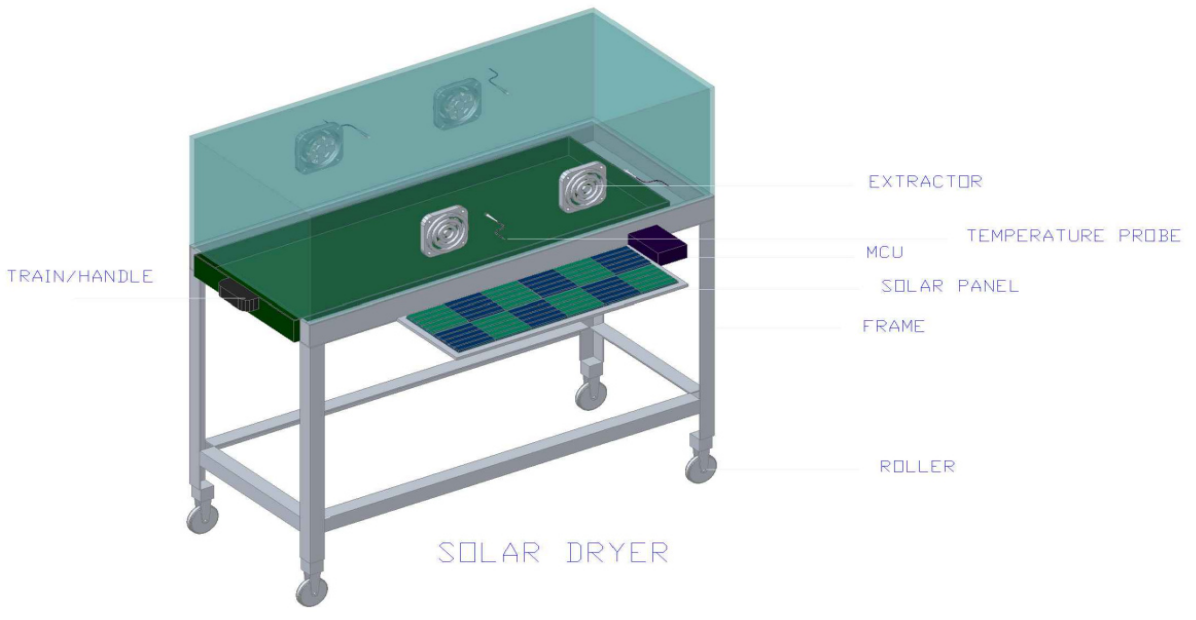

Figure 2: The Developed Automated Solar Thermal Hybrid Dryer

The seasonality of fruits and vegetables makes it impossible to consume and use them throughout the year, thus numerous processing efforts have been made to offer an alternative to their fresh consumption and application. Solar energy is one of the widely used renewable energy sources in drying. Drying of vegetables and fruits using renewable energy such as solar drying has less environmental impact(Tiwari, 2011). To prolong their availability on the market, the proposed hybrid dryer is considered one of the most environmentally friendly and sustainable means of drying agricultural produce. The hybrid dryer is an alternative to biomass dryer, steam dryer and electrical dryers. This type of dryer consists of a drying chamber that is covered by transparent cover made of Perspex (acrylic) material. Hence, the Perspex box which is rectangular in shape reduces direct convective losses to the surroundings and increases temperature inside the solar collector and the dryer. The drying chamber is a rectangular, shallow, insulated box with holes in it to allow air to enter and leave the box. More specifically, the hybrid dryer is designed based on the following consideration:

i. $\quad$ Selected fruits and vegetables which are predominant in the area or community; fruits Orange, Banana and Mangoes; Vegetables - Onion, Cabbage, Tomatoes and Pumpkin leaves and were used for each experiment.

ii. Locally available material resources for the fabrication and construction of the hybrid dryer.

iii. Inlet drying air temperature of the dryer in the range of $40{ }^{\circ} \mathrm{C}-109{ }^{\circ} \mathrm{C}$.

iv. Temperature control of drying air is obtained by the speed of the extractor.

v. In the design and fabrication of the solar collector and dryer, basic parameters such as economic efficiency and thermal properties would equally be taken into consideration.

\subsection{Machine Description}

The proposed hybrid dryer consists of solar thermal collector and drying chamber as shown in the Figure 2, a circulation fan (cum extractor), four temperature probes (two each for the collector and dryer unit), control panel, Li-on Battery Bank, Micro Controller Units (MCU), LCD, Collection Tray and Solar PV. The detailed schematic diagrams of the system are shown in the diagrams in the appendix. This system can provide a drying air temperature of up to $105^{\circ} \mathrm{c}$.

The solar thermal collector was constructed with acrylic material which has a high thermal permeability and was designed as a rectangular cuboid with a length of $1.8 \mathrm{~m}$, width of $0.9 \mathrm{~m}$ and a height of $0.4 \mathrm{~m}$ to take the sunlight straight from every possible direction. The total surface area of the rectangular cuboid was calculated as $3.5 \mathrm{~m}^{2}$. Thus, the heat of the air in the collector is anticipated to reach a high temperature in a short time and as such a fast-drying period could be achieved, which is important in food drying. In order to provide air circulation, the collector was placed on top of the stand with a height of $0.5 \mathrm{~m}$ and air inlet channels were opened at the 
bottom surface of the collector.

Bottom surface of the collector was painted with black enamel (usually bitumen). In order to send warm air from the solar collector to the drying chamber, the carrier Perspex rectangular channel $(0.45 \mathrm{~m}$ by $0.15 \mathrm{~m})$ was placed on the side surface of the rectangular collector where the temperature is the highest and attached to the drying chamber. Two temperature probes each were used to measure the temperature values of the collector and dryer respectively. The bottom part of the collector and the surrounding of the carrier channel are insulated to prevent heat losses.

Four speed-adjustable fans with 2-Watt power capacity were used inside the Perspex duct. The complete box forms the collection and drying chamber and a temperature probe was connected to the duct outlet to measure the temperature in the drying chamber and a relative humidity (RD) sensor was used to measure the hot air velocity entering the drying chamber. The measured values were read out on the LCD device and recorded using the data logger and stored in a Micro SD card, all powered by a rechargeable Lithium-ion packed battery system Hence, the system is termed hybrid because two sources of energy (mains supply and solar energy) that powers the system.

\subsection{Pre-design Experiments}

Certain preliminary experiments were carried out prior to the design and fabrication of the system to determine some basic design parameters to improve the concept of the hybrid dryer. This covers the drying qualities of the chosen fruits and vegetables, as determined by literature reviews and laboratory tests. The optimal drying temperatures for the fruits and vegetables, as well as other features of the fruits and vegetables, were observed. The workshop for Agricultural and Bioenvironmental Engineering was established at Auchi Polytechnic in Auchi, Edo State, to conduct the experiment. The produce for the drying experiment came from a local market, and it was chosen based on seasonal availability and consumption. The drying trial for dehydrating the produce was conducted after the fabrication and construction of the hybrid dryer. During the drying process, the moisture loss of the various samples was determined by a means of testing instruments. Following the fabrication and construction of the hybrid dryer, a drying trial for dehydrating the produce was done. Using testing devices, the moisture loss of the individual samples was evaluated during the drying process.

The solar irradiation or sun constant of the project site was determined. Solar irradiation is the preatmosphere energy in direction of the radiation coming from the sun, perpendicular to the unit area at unit time(Hossain et al., 2018). According to Khan, Asif, \& Stach (2017) solar irradiance is the power per unit area received from the Sun in the form of electromagnetic radiation as measured in the wavelength range of the measuring instrument. The solar irradiance is measured in watt per square metre $\left(\mathrm{W} / \mathrm{m}^{2}\right)$ in SI units $(\mathrm{Khan}$ et al., 2017). The intensity of the radiation on top of the collector for a location like in the Federal Polytechnic Auchi, 0704' 03", 06 16'04", Edo, Nigeria was determined from the Global Solar Atlas as 2,462 W/m².(Solargis, 2021)

Yam and tomatoes slices were used in the experimental tests of the hybrid system, for open sun drying and, also, oven drying. Firstly, the moisture content, drying temperature and the duration of drying (4hours 30 minutes) of the two selected produce (yam and tomatoes) were determined from the first-two systems (Open-Sun Drying and Oven Drying).

Air temperature (ambient temperature, collector inlet temperature, and dryer temperature), radiation intensity, and air velocity were determined using the data logging system powered by Arduino kits and Java script, as were the air the temperature inside the dryer chamber. Relative humidity sensors were installed in the drying unit section. During the drying process, the temperature and relative humidity in the solar dryer were recorded at 45 minutes intervals at six (6) runs, making a total of 270 minutes (4hours and 30 minutes) during the experiments with the data collected in the Bluetooth Electronics App and a Micro SD Card. Data were averaged for 45 minutes prior to analysis using Microsoft Excel Spreadsheet.

To determine the thermal efficiency of the hybrid dryer, some performances index have to be determined. The thermal efficiency of a solar collector is the ratio of useful heat gain to the solar radiation incident on the plane of the collector(Fudholi et al., 2013). According to Fudholi et al., (2013) thermal efficiency is mathematically defined as follows:

$$
\eta_{c}=\frac{m C\left(T_{o}-T_{i}\right)}{A_{c} S} \times 100 \%,
$$

where $m$ : mass flow rate $(\mathrm{kg} / \mathrm{s}), C$ : specific heat of air $(\mathrm{J} / \mathrm{kg} \circ \mathrm{C}), A_{c}$ : collector area $\left(\mathrm{m}^{2}\right), T_{i}$ : inlet air temperature $\left({ }^{\circ} \mathrm{C}\right), T_{o}$ : outlet air temperature $\left({ }^{\circ} \mathrm{C}\right)$, and $S$ : solar radiation intensity $\left(\mathrm{W} / \mathrm{m}^{2}\right)$. The drying efficiency of the hybrid system is defined as the ratio of the energy needed to evaporate moisture to the heat provided to the dryer(Fudholi et al., 2013). The heat supplied to the dryer for the solar collector is the solar radiation event that happens on the solar collector. The drying quality of the system is an indicator of the overall efficacy of the 
drying system. Typical values are expected for forced convection dryers. The energy used by the fan/blower should be taken into account by measuring the device performance for forced convection solar dryers. The following expression can then be used(Daghigh et al., 2020):

$$
\eta_{p}=\frac{W L}{A_{c} S+P_{f}},
$$

where $L$ : latent heat of vaporization of water at exit air temperature $(\mathrm{J} / \mathrm{kg}), W:$ mass of water evaporated from the product $(\mathrm{kg})$, and $P_{f}$ : power fan $(\mathrm{W})$. The mass of water removed $(W)$ from a wet product can be calculated as follow(Daghigh et al., 2020):

$$
W=\frac{m_{o}\left(M_{i}-M_{f}\right)}{100-M_{f}}
$$

Equation 3.3

where $m_{o}$ : initial total crop mass $(\mathrm{kg}), M_{i}$ : initial moisture content fraction on wet basis, and $M_{f}$ : the final moisture content fraction on wet basis.

Now, the time savings in drying the selected produce using the hybrid solar dryer compared with open sun drying can be evaluated. The performance of hybrid solar dryer compared with open sun drying can be calculated using the following equation(Fudholi et al., 2013):

i.e. Saving in drying time $(\%)$ is given as;

$$
\frac{t_{\mathrm{OS}}-t_{\mathrm{SD}}}{t_{\mathrm{OS}}} \times 100 \text { : }
$$

Equation 3.4

where $t_{\mathrm{OS}}$ : time taken for drying the product in open sun $(\mathrm{h})$ and $t_{\mathrm{SD}}$ : time taken for drying in solar drying (h).

\subsection{Statistical Analysis}

The results of specific energy consumption, temperature and drying time was analyzed Microsoft Excel spreadsheet using appropriate modelling tools.

\section{Results and discussion}

\subsection{Performances Index of the Hybrid Dryer}

The drying process using the three systems (Open-Sun Drying, Oven Drying and Hybrid Dryer) was carried out from 9:00 AM to 5:00 PM, using only crops such as yam and tomatoes (200 grams each). Due to time constraints, we could only carryout tests on yam and tomatoes produce, which is a departure from the earlier intent for fruits and vegetables. The two-crop produce (yam and tomatoes) were each sliced at equal thickness, respectively, to allow for uniformity of drying. The solar dryer was turned off during the night. The daily mean values of drying chamber air temperature, drying chamber relative humidity, and solar radiation during the 4hours 30 minutes (45 minutes weighing intervals) period used for each test, varied from approximately 40 to 60 ${ }^{\circ} \mathrm{C}, 5 \%$ to $30 \%$, and 2450 to $2,462 \mathrm{~W} / \mathrm{m}^{2}$, respectively as shown in Figure 3.1 . The drying temperature and relative humidity under solar drying varied continuously with increasing drying time. The results revealed that the drying temperature in hybrid solar dryer was greater than the ambient temperature, whereas the relative humidity under this system was lower than the ambient relative humidity.

In addition, the drying temperature and relative humidity values significantly differed at approximately $15^{\circ}$ $\mathrm{C}$ and $30 \%$, respectively, within the 4 hours 30 minutes drying period. This explicitly indicates that the drying rate (DR) in the hybrid solar dryer is higher than that in open sun drying. On the other hand, the efficiency of the collector varied from $5.66 \%$ to $50.36 \%$, with the average value of approximately $23.74 \%$, at the drying mass flow rate of $19.74 \mathrm{~kg} / \mathrm{s}$. The thermal efficiency rates for the 4 hours 30 minutes of drying are shown in Figure 3.2 , which illustrates that the thermal efficiency of the collector is increased at low solar radiation (Table 3.1-3.4).

\subsection{Drying Curves}

The results of the drying kinetic curves, namely, the drying curves, the thermal efficiency curve curve of both yam and tomatoes slices using open sun drying, oven drying and the hybrid solar dryer are shown in Figures 3.13.8. The drying curve showed the profile change in moisture content $(M)$ versus drying time $(t)$, Figure 3.1-3.7 demonstrates a reduction in moisture content (dry basis) from the hybrid solar dryer to the open sun drying. At low drying time (under open sun drying), the moisture content of the selected crop produce (yam and tomatoes) increased, slowing down the drying process as the drying time increased. 
Table 3.1: Performance of Hybrid Solar Dryer for Tomato Slices at 45 Minutes Interval for Hybrid Dryer

\begin{tabular}{ccccccccc} 
Time (Min) & RD (\%) & $\begin{array}{c}\text { Avg Dryer } \\
\text { Temp }\left({ }^{\mathbf{0}} \mathbf{C}\right)\end{array}$ & $\begin{array}{c}\text { Avg } \\
\text { Collector } \\
\text { Temp }\left({ }^{\mathbf{0}} \mathbf{C}\right)\end{array}$ & $\begin{array}{c}\text { Weight } \\
\text { BD } \\
\text { (grams) }\end{array}$ & $\begin{array}{c}\text { Weight } \\
\text { AD } \\
\text { (grams) }\end{array}$ & Mwb \% & Mdb \% \\
\hline $\mathbf{4 5 . 0}$ & 33.0 & 60.31 & 53.34 & 200.00 & 198.4 & 0.8 & 0.81 \\
\hline $\mathbf{9 0 . 0}$ & 31.0 & 58.69 & 53.55 & 200.00 & 191.2 & 4.4 & 4.60 \\
\hline $\mathbf{1 3 5 . 0}$ & 27.0 & 58.43 & 44.11 & 200.00 & 186.0 & 7.0 & 7.53 \\
\hline $\mathbf{1 8 0 . 0}$ & 22.0 & 60.47 & 47.56 & 200.00 & 178.8 & 10.6 & 11.57 \\
\hline $\mathbf{2 2 5 . 0}$ & 28.0 & 64.94 & 42.94 & 200.00 & 170.2 & 14.9 & 17.51 \\
\hline $\mathbf{2 7 0 . 0}$ & 25.0 & 48.20 & 35.06 & 200.00 & 163.4 & 18.3 & 22.4 \\
\hline
\end{tabular}

*Mwb = Moisture content on wet basis, $M d b=$ Moisture content on dry basis

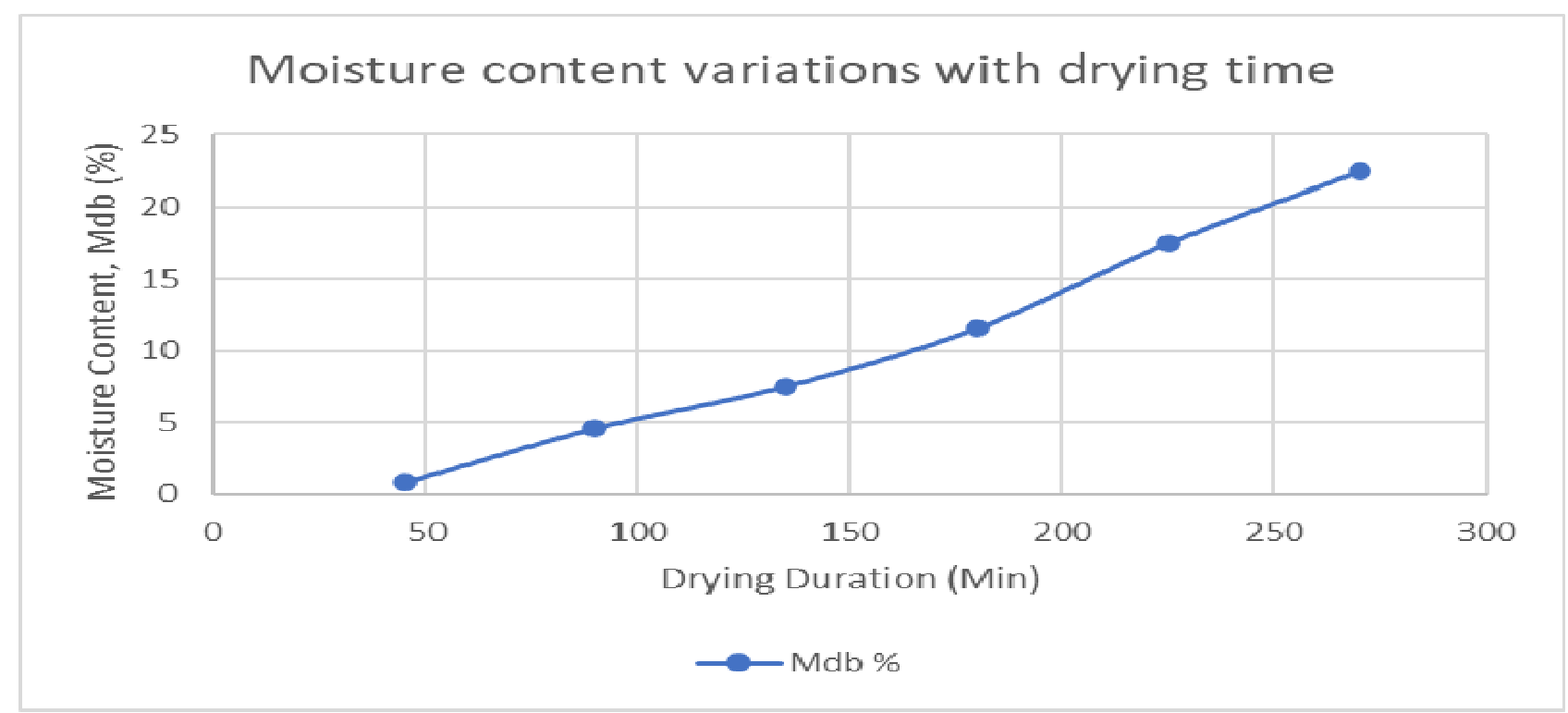

Figure 3.1: Moisture content variation with drying time (dry basis) for tomatoes slices

Table 3.2: Performance of Hybrid Solar Dryer for Yam Slices at 45 Minutes Interval for Hybrid dryer

\begin{tabular}{|c|c|c|c|c|c|}
\hline $\begin{array}{l}\text { Avg Dryer } \\
\text { Temp }\left({ }^{\circ} \mathrm{C}\right)\end{array}$ & $\begin{array}{l}\text { Avg Collector } \\
\text { Temp }\left({ }^{\circ} \mathrm{C}\right)\end{array}$ & $\begin{array}{c}\text { Weight BD } \\
\text { (grams) }\end{array}$ & $\begin{array}{c}\text { Weight AD } \\
\text { (grams) }\end{array}$ & Mwb \% & Mdb \% \\
\hline 60.31 & 53.34 & 200.00 & 196.30 & 1.85 & 1.88 \\
\hline 58.69 & 53.55 & 200.00 & 190.00 & 5.00 & 5.26 \\
\hline 58.43 & 44.11 & 200.00 & 183.80 & 8.10 & 8.84 \\
\hline 60.47 & 47.56 & 200.00 & 176.80 & 11.60 & 13.12 \\
\hline 64.94 & 42.94 & 200.00 & 171.30 & 14.35 & 16.75 \\
\hline 48.20 & 35.06 & 200.00 & 165.30 & 17.35 & 20.10 \\
\hline
\end{tabular}

$* M w b=$ Moisture content on wet basis, Mdb = Moisture content on dry basis 


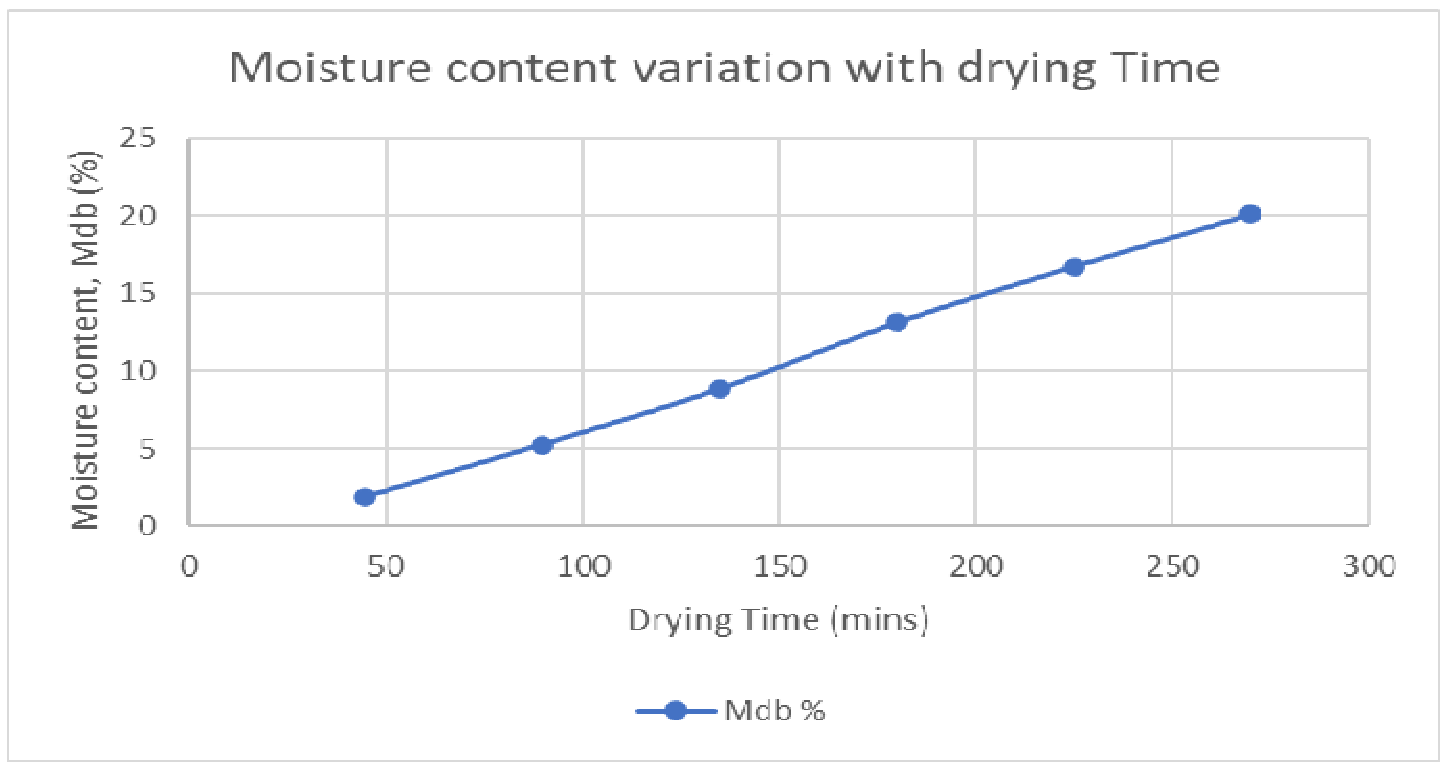

Figure 3.2: Moisture content variation with drying time (dry basis) for yam slices

Table 3.3: Performance of Oven dryer for Tomatoes Slices at 45 Minutes Interval

\begin{tabular}{cccccc}
\hline $\begin{array}{c}\text { OvenTemp } \\
\left({ }^{\circ} \mathbf{C}\right)\end{array}$ & $\begin{array}{c}\text { Time } \\
\text { (Min) }\end{array}$ & $\begin{array}{c}\text { Weight BD } \\
\text { (grams) }\end{array}$ & $\begin{array}{c}\text { Weight AD } \\
\text { (grams) }\end{array}$ & Mwb \% & Mdb \% \\
\hline $\mathbf{3 4 . 5}$ & 45.0 & 200.0 & 197.2 & 1.14 & 1.42 \\
\hline $\mathbf{3 6 . 3}$ & 90.0 & 200.0 & 191.8 & 4.10 & 4.28 \\
\hline $\mathbf{3 8 . 5}$ & 135.0 & 200.0 & 186.7 & 6.65 & 7.12 \\
\hline $\mathbf{4 0 . 0}$ & 180.0 & 200.0 & 181.2 & 9.40 & 10.38 \\
\hline $\mathbf{4 0 . 0}$ & 225.0 & 200.0 & 175.3 & 12.35 & 19.09 \\
\hline $\mathbf{3 8 . 0}$ & 270.0 & 200.0 & 170.0 & 15.0 & 17.65 \\
\hline
\end{tabular}

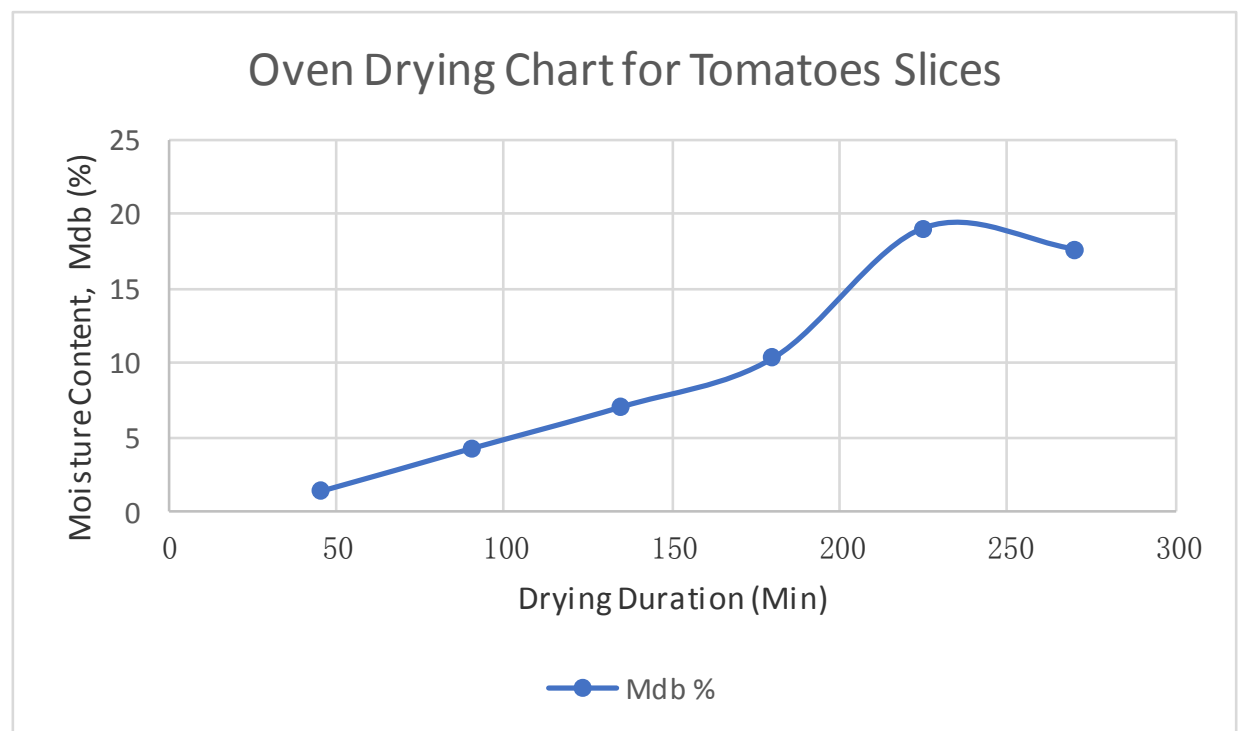

Figure 3.3: Moisture content variation with drying time (dry basis) for Tomatoes slices under Oven drying 
Table 3.4: Performance of Oven Drying for Yam Slices at 45 Minutes Interval

\begin{tabular}{cccccc}
\hline $\begin{array}{c}\text { Oven Temp } \\
\left({ }^{\circ} \mathbf{C}\right)\end{array}$ & $\begin{array}{c}\text { Time } \\
\text { (Min) }\end{array}$ & $\begin{array}{c}\text { Weight BD } \\
\text { (grams) }\end{array}$ & $\begin{array}{c}\text { Weight AD } \\
\text { (grams) }\end{array}$ & Mwb \% & Mdb \% \\
\hline $\mathbf{3 4 . 5}$ & 45.0 & 200.0 & 198.3 & 0.86 & 0.85 \\
\hline $\mathbf{3 6 . 3}$ & 90.0 & 200.0 & 189.2 & 5.81 & 5.40 \\
\hline $\mathbf{3 8 . 5}$ & 135.0 & 200.0 & 180.0 & 11.11 & 10.00 \\
\hline $\mathbf{4 0 . 0}$ & 180.0 & 200.0 & 178.0 & 12.23 & 11.00 \\
\hline $\mathbf{4 0 . 0}$ & 225.0 & 200.0 & 171.3 & 16.75 & 14.35 \\
\hline $\mathbf{3 8 . 0}$ & 270.0 & 200.0 & 169.1 & 15.45 & 15.45 \\
\hline
\end{tabular}

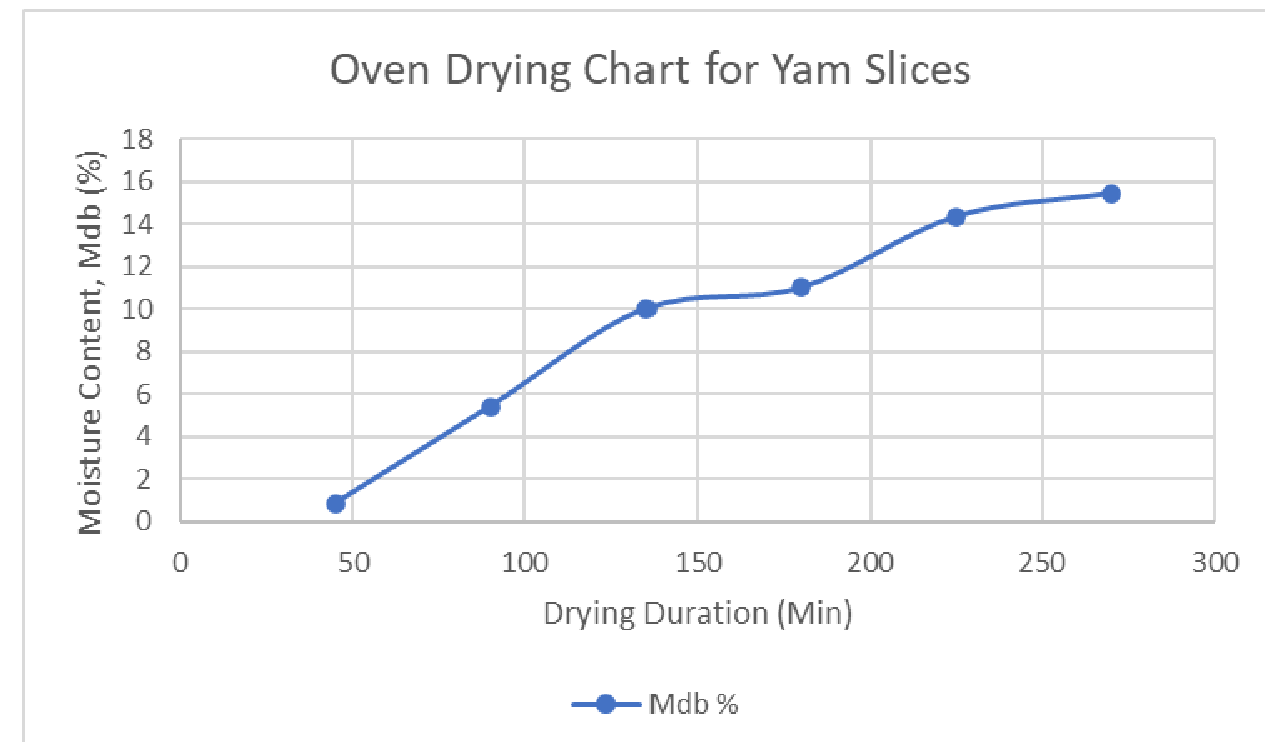

Figure 3.4: Moisture content variation with drying time (dry basis) for yam slices under Oven drying

The oven drying tests were carried out to serve as a control in observing and evaluating the temperatures and moisture content values for both tomatoes and yam under the open sun drying and the hybrid drying system. Now, the open sun drying values for both tomatoes and yam as indicated in the Tables 3.5-3.6 shows that the moisture content data collated from the Oven drying (Tables 3.3-3.4) and that from the Open sun drying are dissimilar at observatory level.

Table 3.5: Performance of Open Drying for Tomatoes Slices at 45 Minutes Interval

\begin{tabular}{cccccc}
\hline $\begin{array}{c}\text { SunTemp } \\
\left({ }^{\mathbf{}} \mathbf{C}\right)\end{array}$ & Time (Min) & $\begin{array}{c}\text { Weight BD } \\
\text { (grams) }\end{array}$ & $\begin{array}{c}\text { Weight AD } \\
\text { (grams) }\end{array}$ & Mwb \% & Mdb \% \\
\hline $\mathbf{3 4 . 0}$ & 45.0 & 200.0 & 164.9 & 17.55 & 0.91 \\
\hline $\mathbf{3 4 . 0}$ & 90.0 & 200.0 & 155.3 & 22.35 & 6.89 \\
\hline $\mathbf{3 6 . 0}$ & 135.0 & 200.0 & 145.9 & 27.05 & 13.12 \\
\hline $\mathbf{3 8 . 0}$ & 180.0 & 200.0 & 142.4 & 28.8 & 19.58 \\
\hline $\mathbf{3 8 . 0}$ & 225.0 & 200.0 & 118.1 & 40.95 & 24.47 \\
\hline $\mathbf{3 6 . 0}$ & 270.0 & 200.0 & 109.2 & 45.4 & 28.53 \\
\hline
\end{tabular}




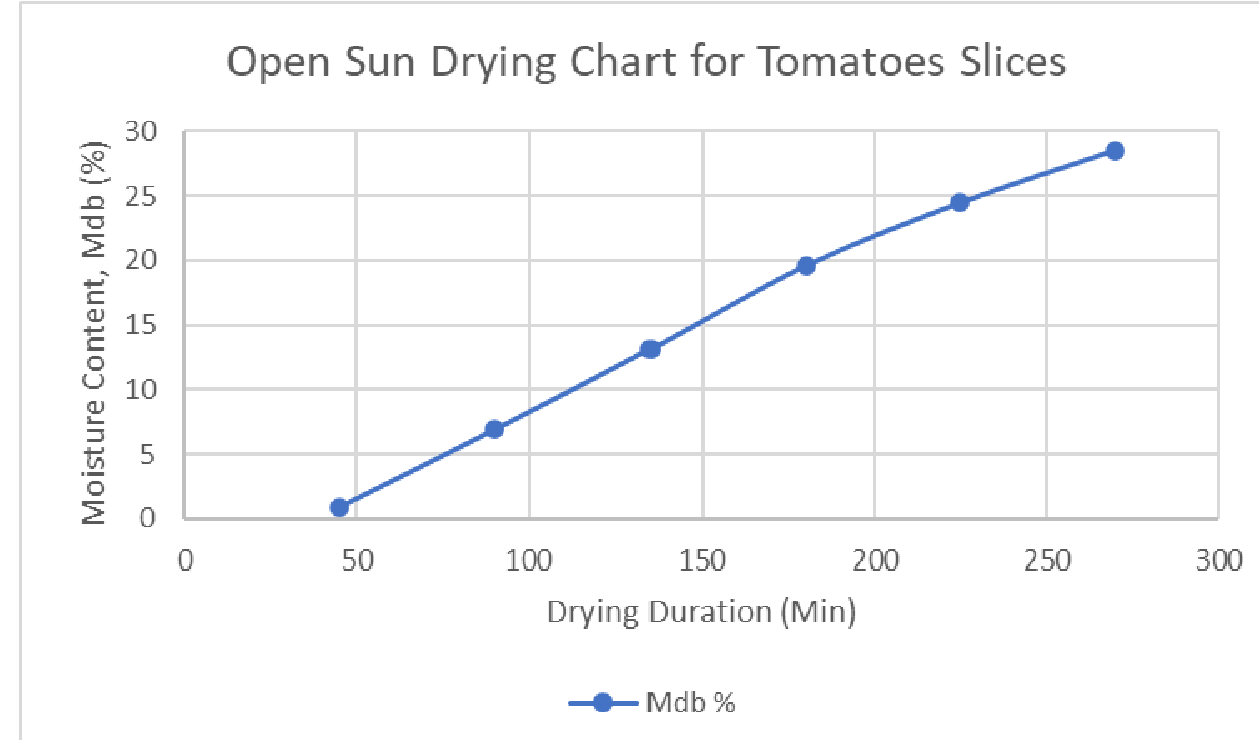

Figure 3.5: Moisture content variation with drying time (dry basis) for tomatoes slices under open drying

Table 3.6: Performance of Open sun drying for Yam Slices at 45 Minutes Interval

\begin{tabular}{cccccc}
\hline $\begin{array}{c}\text { SunTemp } \\
\left({ }^{\mathbf{}} \mathbf{C}\right)\end{array}$ & Time (Min) & $\begin{array}{c}\text { Weight BD } \\
\text { (grams) }\end{array}$ & $\begin{array}{c}\text { Weight AD } \\
\text { (grams) }\end{array}$ & Mwb \% & Mdb \% \\
\hline $\mathbf{3 4 . 0}$ & 45.0 & 200.0 & 198.2 & 0.89 & 0.93 \\
\hline $\mathbf{3 4 . 0}$ & 90.0 & 200.0 & 187.1 & 6.45 & 6.89 \\
\hline $\mathbf{3 6 . 0}$ & 135.0 & 200.0 & 176.8 & 11.60 & 13.12 \\
\hline $\mathbf{3 8 . 0}$ & 180.0 & 200.0 & 170.1 & 14.95 & 17.58 \\
\hline $\mathbf{3 8 . 0}$ & 225.0 & 200.0 & 163.3 & 15.35 & 22.47 \\
\hline $\mathbf{3 6 . 0}$ & 270.0 & 200.0 & 155.6 & 22.20 & 25.53 \\
\hline
\end{tabular}

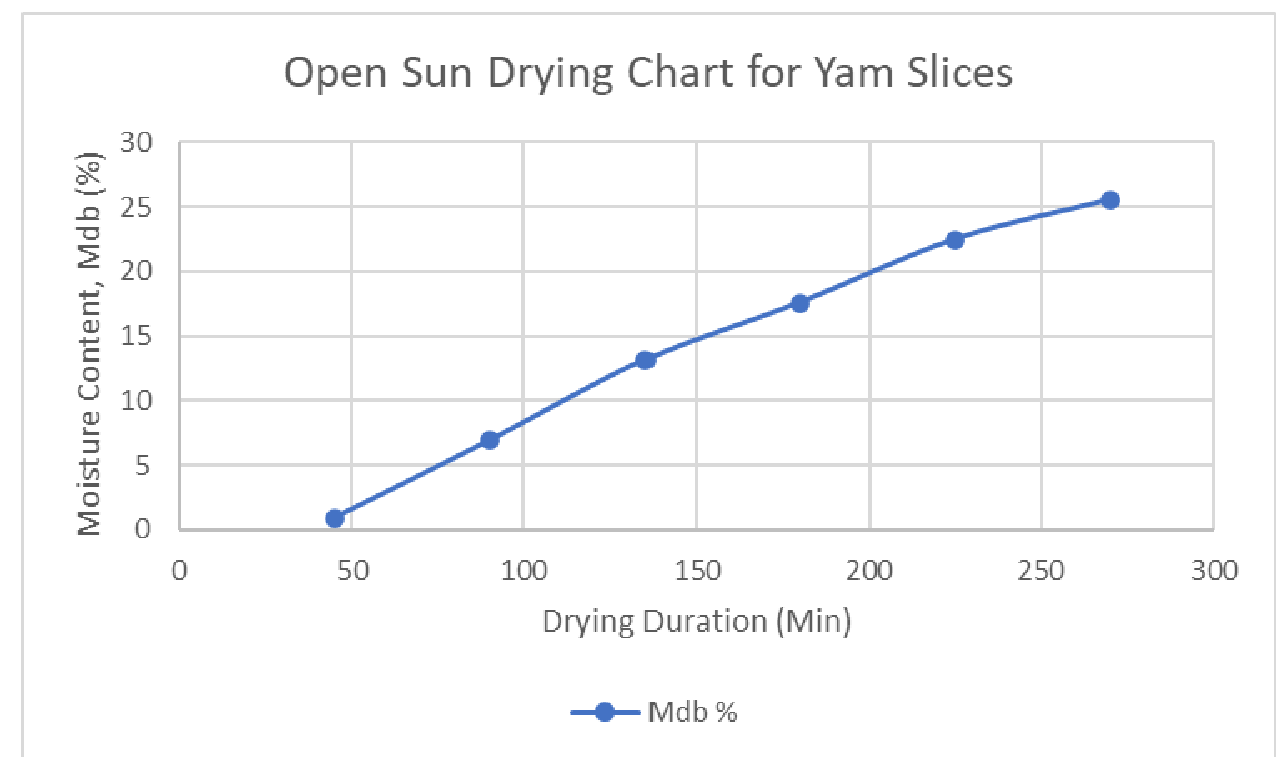

Figure 3.6: Moisture content variation with drying time (dry basis) for yam slices under open drying 


\subsection{Thermal Efficiency}

Table 3.7: Thermal Efficiency of the Hybrid Solar Dryer for Tomato Slices

\begin{tabular}{|c|c|c|c|c|c|c|c|c|}
\hline $\begin{array}{l}\text { Time } \\
\text { (Min) }\end{array}$ & $\begin{array}{l}\text { RD } \\
(\%)\end{array}$ & $\begin{array}{l}\text { Avg Dryer } \\
\text { Temp }\left({ }^{\circ} \mathrm{C}\right)\end{array}$ & $\begin{array}{l}\text { Avg Collector } \\
\operatorname{Temp}\left({ }^{\circ} \mathrm{C}\right)\end{array}$ & $\begin{array}{c}\text { Weight BD } \\
\text { (grams) }\end{array}$ & $\begin{array}{c}\text { Weight } \\
\text { AD } \\
\text { (grams) }\end{array}$ & $\begin{array}{c}\text { Mwb } \\
\%\end{array}$ & $\begin{array}{c}\text { Mdb } \\
\%\end{array}$ & $\eta_{c}(\%)$ \\
\hline 45.0 & 33.0 & 60.31 & 53.34 & 200.00 & 198.4 & 0.8 & 0.81 & 5.66 \\
\hline 90.0 & 31.0 & 58.69 & 53.55 & 200.00 & 191.2 & 4.4 & 4.6 & 11.76 \\
\hline 135.0 & 27.0 & 58.43 & 44.11 & 200.00 & 186.0 & 7.0 & 7.53 & 32.78 \\
\hline 180.0 & 22.0 & 60.47 & 47.56 & 200.00 & 178.8 & 10.6 & 11.57 & 29.55 \\
\hline 225.0 & 28.0 & 64.94 & 42.94 & 200.00 & 170.2 & 14.9 & 17.51 & 50.36 \\
\hline 270.0 & 25.0 & 40.20 & 35.06 & 200.00 & 163.4 & 18.3 & 22.4 & 12.38 \\
\hline & & $\begin{array}{l}w b=\text { Moistu } \\
\text { able 3.8: The }\end{array}$ & $\begin{array}{l}\text { ntent on wet bas } \\
\text { Efficiency of } t\end{array}$ & Iybrid Solar & er for $Y \mathbf{a}$ & $\begin{array}{l}\text { y basis } \\
\text { Slices }\end{array}$ & & \\
\hline $\begin{array}{l}\text { Time } \\
\text { (Min) }\end{array}$ & $\begin{array}{l}\text { RD } \\
(\%)\end{array}$ & $\begin{array}{l}\text { Avg Dryer } \\
\text { Temp }\left({ }^{\circ} \mathrm{C}\right)\end{array}$ & $\begin{array}{l}\text { Avg Collector } \\
\operatorname{Temp}\left({ }^{\circ} \mathrm{C}\right)\end{array}$ & $\begin{array}{c}\text { Weight BD } \\
\text { (grams) }\end{array}$ & $\begin{array}{c}\text { Weight } \\
\text { AD } \\
\text { (grams) }\end{array}$ & $\begin{array}{c}\text { Mwb } \\
\%\end{array}$ & $\begin{array}{c}\text { Mdb } \\
\%\end{array}$ & $\eta_{\mathbf{c}(\%)}$ \\
\hline 45.0 & 33.0 & 60.31 & 53.34 & 200.00 & 196.30 & 1.85 & 1.88 & 5.66 \\
\hline 90.0 & 31.0 & 58.69 & 53.55 & 200.00 & 190.00 & 5.00 & 5.26 & 11.76 \\
\hline 135.0 & 27.0 & 58.43 & 44.11 & 200.00 & 183.80 & 8.10 & 8.84 & 32.78 \\
\hline 180.0 & 22.0 & 60.47 & 47.56 & 200.00 & 176.80 & 11.60 & 13.12 & 29.55 \\
\hline 225.0 & 28.0 & 64.94 & 42.94 & 200.00 & 171.30 & 14.35 & 16.75 & 50.36 \\
\hline 270.0 & 25.0 & 40.20 & 35.06 & 200.00 & 165.30 & 17.35 & 20.10 & 12.38 \\
\hline
\end{tabular}

$* M w b=$ Moisture content on wet basis, $M d b=$ Moisture content on dry basis

From the above tables (3.7-3.8) the average thermal efficiency of the dryer for a 4 hours 30 minutes trials in 6 runs is $23.74 \%$. This value was computed from the equation 3.1. Using the data from the table 3.7 or 3.8 , the thermal efficiency curve was obtained and elucidated in the figure 3.7 below. The curve shows that a higher thermal efficiency was obtained at the $5^{\text {th }}$ run $(225$ minutes under the hybrid dryer) and at collector and dryer temperatures of 42.94 and 64.94 degrees Celsius respectively. Fudholi et al., (2013), designed a similar dryer for chilli with a thermal efficiency of $28 \%$.

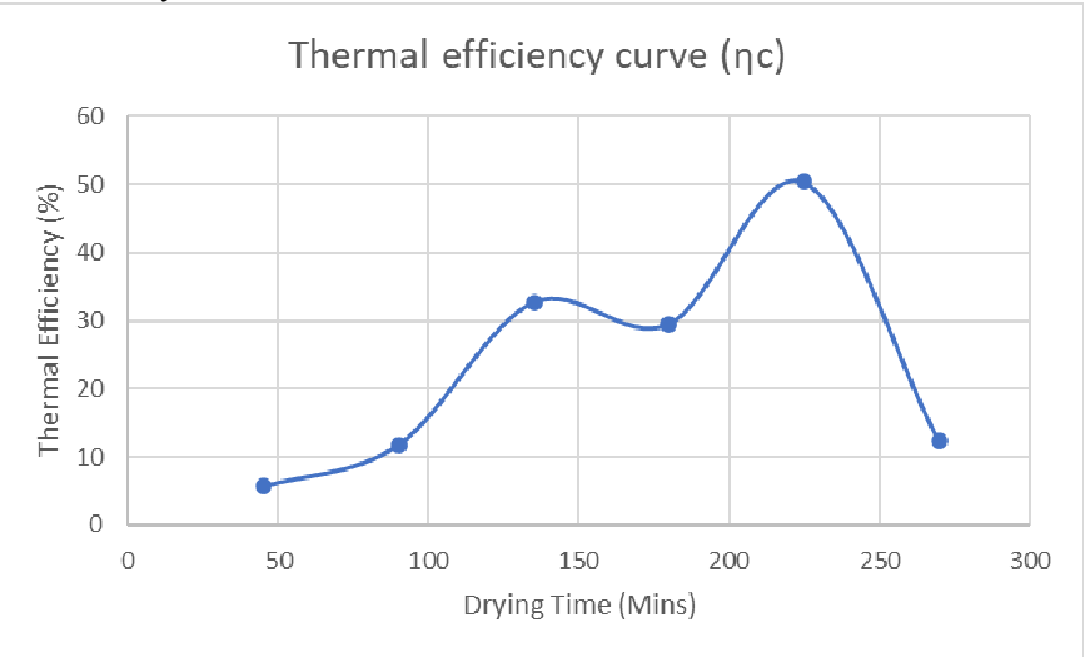

Figure 3.7: Thermal efficiency curve

\subsection{Conclusion}

Nigeria is scaling up its energy supply to overcome supply shortages in the short term and meet the demand to fuel economic growth. Solar drying is one of the most efficient and cost-effective, renewable, and sustainable technologies to conserve agricultural products in Nigeria and other parts of the world with abundant sunshine. This research work focused on the automation of a novel solar dryer that is powered by renewable energy and mains supply. To achieve our objectives, different types of solar dryers that are widely used in the world were reviewed. In addition, the pre-eminent effects of their use on product quality, as well as their economic, 
environmental, and social impacts, were reviewed. Upon fabrication and performance evaluation, we obtained a thermal efficiency of $23.74 \%$, at the average solar radiation of approximately $2462 \mathrm{~W} / \mathrm{m}^{2}$ and air flow rate of $19.74 \mathrm{~kg} / \mathrm{s}$, the collector area was $3.52 \mathrm{~m}^{2}$. The whole system was automated and the data logging system aided in the effective collection and evaluation of our data. However, there were limitations in determine the time savings in drying using solar drying compared with open sun drying. The performance of hybrid solar drying compared with open sun drying was not computed because time constraints and the duration (trial run was fixed in all cases).

\subsection{Recommendation}

To optimize the total efficiency of the system like the complete results of the drying rate curves, and the characteristic of the drying curve, of several fruits and vegetables using open sun drying and the hybrid solar dryer need to be carried out. Also, the duration needs to be a dependent variable across longer periods unlike the 45 minutes interval in this research.

\section{Acknowledgements}

The authors acknowledge and appreciate the Tertiary Education Trust Fund (TETFUND) Nigeria for the provision of resources for this work.

\section{REFERENCES}

Ahmadi, A., Das, B., Ehyaei, M. A., Esmaeilion, F., el Haj Assad, M., Jamali, D. H., Koohshekan, O., Kumar, R., Rosen, M. A., Negi, S., Bhogilla, S. S., \& Safari, S. (2021). Energy, exergy, and techno-economic performance analyses of solar dryers for agro products: A comprehensive review. Solar Energy, 228. https://doi.org/10.1016/j.solener.2021.09.060

Blimpo, M. P., \& Cosgrove-Davies, M. (2019). Electricity Access in Sub-Saharan Africa Uptake, Reliability, and Complementary Factors for Economic Impact.

Daghigh, R., Shahidian, R., \& Oramipoor, H. (2020). A multistate investigation of a solar dryer coupled with photovoltaic thermal collector and evacuated tube collector. Solar Energy, 199, 694-703. https://doi.org/10.1016/j.solener.2020.02.069

Fudholi, A., Othman, M. Y., Ruslan, M. H., \& Sopian, K. (2013). Drying of Malaysian Capsicum annuum L. (Red Chili) Dried by Open and Solar Drying. International Journal of Photoenergy, 2013, 1-9. https://doi.org/10.1155/2013/167895

Hossain, M. Z., Alam, M. M., Bin Hossain, M. F., Sarker, M., Awal, M. A., \& Jahan, N. (2018). Performance evaluation of a cabinet solar dryer for drying red pepper in Bangladesh. Journal of Agricultural Engineering, 49(2), 100-109. https://doi.org/10.4081/jae.2018.774

Lamrani, B., Draoui, A., \& Kuznik, F. (2021). Thermal performance and environmental assessment of a hybrid solar-electrical wood dryer integrated with Photovoltaic/Thermal air collector and heat recovery system. Solar Energy, 221. https://doi.org/10.1016/j.solener.2021.04.035

Khan, M. M. A., Asif, M., \& Stach, E. (2017). Rooftop PV potential in the residential sector of the kingdom of Saudi Arabia. Buildings, 7(2), 1-20. https://doi.org/10.3390/buildings7020046

Solargis. (2021). Global Solar Atlas-Auchi. Global Solaratlas.Info/Map. https://globalsolaratlas.info/map?s=7.067445,6.267666\&m=site \&c $=7.067445,6.267666,11$

Mohammed, S., Fatumah, N., \& Shadia, N. (2020). Drying performance and economic analysis of novel hybrid passive-mode and active-mode solar dryers for drying fruits in East Africa. Journal of Stored Products Research, 88. https://doi.org/10.1016/j.jspr.2020.101634

Teale, Y. (2021, October 13). Reducing Postharvest Loss. GAIN.

Tiwari, G. N. , R. K. M. (2011). Advanced Renewable Energy Sources (2nd ed., Vol. 1). RSC Publishing.

Udomkun, P., Romuli, S., Schock, S., Mahayothee, B., Sartas, M., Wossen, T., Njukwe, E., Vanlauwe, B., \& Müller, J. (2020). Review of solar dryers for agricultural products in Asia and Africa: An innovation landscape approach. Journal of Environmental Management, 268. https://doi.org/10.1016/j.jenvman.2020.110730 